\title{
Simultaneous Determination of 2,3,7,8-TCDD and 2,3,7,8-TCDF in Water Samples by LLE-LTP and HPLC-DAD
}

\author{
Lázaro C. Sicupira, ${ }^{a}$ João P. F. Tiago, ${ }^{b}$ Gevany P. de Pinho ${ }^{b}$ and Flaviano O. Silvério ${ }^{(*, b}$ \\ ${ }^{a}$ Instituto de Engenharia, Ciência e Tecnologia, \\ Universidade Federal dos Vales do Jequitinhonha e Mucuri, 39440-000 Janaúba-MG, Brazil \\ ${ }^{b}$ Instituto de Ciências Agrárias, Universidade Federal de Minas Gerais, \\ 39404-547 Montes Claros-MG, Brazil
}

\begin{abstract}
Polychlorinated dibenzo- $p$-dioxins and dibenzofurans are persistent organic pollutants which can mainly be found in the environment in water. These compounds are highly toxic and therefore developing new extraction methodologies that are simpler and cost less is highly desirable. This study aimed to optimize and validate the liquid-liquid extraction with low-temperature partition methodology of 2,3,7,8-tetrachlorodibenzo- $p$-dioxin and 2,3,7,8-tetrachlorodibenzofuran in water samples. The optimum extraction conditions were $8.0 \mathrm{~mL}$ of the acetonitrile and $4.0 \mathrm{~mL}$ of the water, homogenized in a vortex for $1 \mathrm{~min}$ and then maintained at $-20{ }^{\circ} \mathrm{C}$ for $1 \mathrm{~h}$. The analytes recovery percentage was close to $100 \%$ and relative standard deviation was less than $7 \%$. The methodology was precise, accurate, linear at 2.4-5.4 $\mu \mathrm{g} \mathrm{L}^{-1}$, and selective, with a quantification limit of $2.4 \mu \mathrm{g} \mathrm{L}^{-1}$. The optimized methodology was applied in ten real samples and the results showed that these analytes were not detected.
\end{abstract}

Keywords: PCDD/Fs, dioxins, furans, extraction methodologies, low-temperature partition

\section{Introduction}

Polychlorinated dibenzo- $p$-dioxins and dibenzofurans $(\mathrm{PCDD} / \mathrm{Fs})$ are classified as priority pollutants due to their carcinogenic, mutagenic and toxic effects. ${ }^{1-4}$ Their congeners with chlorine atoms in the 2,3, 7 and 8 -positions of the aromatic rings are considered the most toxic and they have been detectable in almost all ecosystems. ${ }^{1,5}$

These compounds are mainly formed by thermal processes involving chlorine organic compounds such as burning urban waste and forest fires. These compounds have also been formed in pulp and paper companies, as well as by chemical and pesticide industries. ${ }^{1,6}$

In general, polychlorinated dioxins and furans are lipophilic substances with low volatility and they show halflives of 7 to 10 years in humans and 25 to 100 years in the environment. ${ }^{7}$ In addition, these compounds are resistant to chemical and biological degradations, therefore they are persistent in the environment. ${ }^{2,8}$ Despite the low solubility in water, PCDD/Fs can be found in aquatic environments such

*e-mail: flavianosilverio@ufmg.br as sea water and fish. ${ }^{9}$ Thus, human exposure to PCDD/Fs can mainly occur through consuming contaminated food or water. ${ }^{1}$

The United States Environmental Protection Agency (USEPA) has defined the maximum residue limit (MRL) for polychlorinated dioxins in drinking water as $0.000000030 \mathrm{mg} \mathrm{L}^{-1}\left(30 \mathrm{pg} \mathrm{L}^{-1}\right){ }^{10}$ In Brazil, the National Council for the Environment (CONAMA) through $357^{11}$ and $430^{12}$ Resolutions does not define the MRL for $\mathrm{PCDD} / \mathrm{Fs}$ in water samples.

The extraction of these compounds from water samples mainly occurs through solid-phase extraction (SPE), ${ }^{13,14}$ solid-phase microextraction (SPME), ${ }^{15,16}$ liquid-phase microextraction (LPME), ${ }^{1}$ cloud-point extraction $(\mathrm{CPE})^{17,18}$ and liquid-liquid extraction (LLE), with the latter being the reference method. ${ }^{19}$

Recently, solid-liquid extraction with low-temperature purification (SLE-LTP) was reported as an easy, fast and efficient methodology for extracting PCDD/Fs from agricultural soil and sewage sludge. ${ }^{20}$ Despite the success of SLE-LTP in the extraction of PCDD/Fs from solid matrices, there are no reports on this methodology for analyzing these compounds in water. 
In aqueous samples, this methodology is called liquidliquid extraction with low-temperature partition (LLELTP). ${ }^{21}$ It consists of adding an organic phase to the aqueous matrix and is based on partitioning analytes between both phases by lowering the temperature to $-20^{\circ} \mathrm{C}$. The sample components are frozen with the aqueous phase, while analytes are extracted by the organic phase which remains liquid. ${ }^{22}$

After extractions, these compounds are analyzed by different techniques such as high resolution gas chromatography coupled to high resolution mass spectrometry (HRGC-HRMS), which has been applied as a reference methodology established by the USEPA. ${ }^{19}$ However, other alternative methodologies have been used such as gas chromatography coupled to mass spectrometry (GC-MS) ${ }^{20}$ gas chromatography coupled to electron capture detection (GC-ECD), ${ }^{1}$ gas chromatography coupled to mass spectrometry with triple quadrupole detector (GC-MS/MS), ${ }^{8}$ high-performance liquid chromatography coupled to ultraviolet detection (HPLC-UV) ) $^{18,23-26}$ and high-performance liquid chromatography coupled to fluorescence detection (HPLC-FD). 17,27

This paper aimed to optimize and validate the liquidliquid extraction with low-temperature partition and analyses by high-performance liquid chromatography coupled a diode array detector method (LLE/LTP-HPLC/DAD) for the determination of 2,3,7,8-tetrachlorodibenzo- $p$-dioxin (2,3,7,8-TCDD) and 2,3,7,8-tetrachlorodibenzofuran $(2,3,7,8-\mathrm{TCDF})$ in water samples.

\section{Experimental}

\section{Reagents and solutions}

HPLC-grade solvents hexane and methanol were purchased from Dinâmica (Brazil), acetonitrile (ACN) from J.T. Baker (USA) and ethyl acetate (AC) from Vetec (Brazil). All solvents were filtered on $0.2 \mu \mathrm{m}$ pore nylon membrane, which was purchased from Supelco (USA). Standard solutions of 2,3,7,8-TCDD $\left(50 \mathrm{mg} \mathrm{L}^{-1}\right)$ and 2,3,7,8-TCDF (50 $\left.\mathrm{mg} \mathrm{L}^{-1}\right)$ were purchased from Cambridge Isotope Laboratories (USA) and Sigma-Aldrich (USA), respectively. Standard stock solutions were prepared at a concentration of $12 \mathrm{mg} \mathrm{L}^{-1}$ and working solutions were prepared at a concentration of $2 \mathrm{mg} \mathrm{L}^{-1}$. All solutions were stored at $-20^{\circ} \mathrm{C}$. Anhydrous sodium sulfate was purchased from Vetec (Brazil) with purity greater than $99 \%$.

\section{Equipment}

The equipment used in the LLE-LTP were a Kindly centrifuge (Brazil), a vortex from Scilogex (USA), a vacuum pump from Prismatec (Brazil) and an analytical scale from Shimadzu (Brazil).

\section{Chromatographic analyses}

Chromatographic analyses were performed in a highperformance liquid chromatograph coupled to a diode array detector (HPLC-DAD, model 1290, Agilent Technologies, Germany). The injection volume was $20 \mu \mathrm{L}$. The variables studied to optimize the analysis conditions are shown in Table 1.

Table 1. Optimized chromatographic conditions

\begin{tabular}{|c|c|}
\hline Parameter & \\
\hline \multirow{3}{*}{ Wavelength / nm } & 200 \\
\hline & 232 \\
\hline & 227 \\
\hline \multirow[b]{2}{*}{ Chromatographic column } & $\begin{array}{c}\text { Kinetex column }(\mathrm{C} 18)(100 \mathrm{~A}, \\
150 \times 4.60 \mathrm{~mm}, 5 \mu \mathrm{m}, \text { Phenomenex })\end{array}$ \\
\hline & $\begin{array}{c}\text { Poroshell } 120 \text { EC-C18 column } \\
(50 \times 4.60 \mathrm{~mm}, 2.7 \mu \mathrm{m} \text {, Agilent } \\
\text { Technologies })\end{array}$ \\
\hline Mobile phase in the isocratic mode & $\begin{array}{l}\text { acetonitrile and water }{ }^{\mathrm{a}} \\
\text { methanol and water }\end{array}$ \\
\hline \multirow{2}{*}{ Flow rate / $\left(\mathrm{mL} \mathrm{min}^{-1}\right)$} & 0.5 \\
\hline & 1.0 \\
\hline \multirow{2}{*}{ Column temperature $/{ }^{\circ} \mathrm{C}$} & 30 \\
\hline & 35 \\
\hline
\end{tabular}

aProportions: 100:0, 95:05, 90:10, 85:15, 80:20, 75:25 and 70:30.

\section{LLE-LTP}

The variable studied to optimize the extraction conditions is shown in Table 2. Extraction percentages in each optimization condition were analyzed by the $t$-test $(p<0.05)$.

Table 2. Parameter evaluated in the LLE-LTP of 2,3,7,8-TCDF and 2,3,7,8-TCDD in water samples

\begin{tabular}{lc}
\hline Parameter & Level \\
\hline Extraction mixture & $8.0 \mathrm{~mL}$ acetonitrile \\
\hline
\end{tabular}

In the optimized methodology, $4.0 \mathrm{~mL}$ of water was added to $22 \mathrm{~mL}$ glass flask and after, spiked with $192 \mu \mathrm{L}$ of standard solutions of 2,3,7,8-TCDF and 2,3,7,8-TCDD at a concentration of $2 \mathrm{mg} \mathrm{L}^{-1}$. Next, $8.0 \mathrm{~mL}$ of extraction mixture was added to the sample (Table 2). The system 
was homogenized in a vortex for $1 \mathrm{~min}$ and then kept at $-20^{\circ} \mathrm{C}$ for $1 \mathrm{~h}$ until complete freezing of the aqueous phase. The liquid (organic) phase of the biphasic system was transferred to a $15 \mathrm{~mL}$ polypropylene tube containing $375 \mathrm{mg}$ of anhydrous sodium sulfate. The system was then homogenized for $1 \mathrm{~min}$ in vortex and centrifuged at $4000 \mathrm{rpm}(2950 \times \mathrm{g})$ for $10 \mathrm{~min}$. Finally, $5.0 \mathrm{~mL}$ of the extract was completely evaporated, resuspended in $600 \mu \mathrm{L}$ of acetonitrile and stored at $4{ }^{\circ} \mathrm{C}$ until analysis by HPLC-DAD. The quantification of the analytes was done by area comparison, using a standard solution with the same concentration.

\section{Methodology validation}

The methodology validation was performed through linearity, matrix effect, selectivity, limit of quantification (LOQ), precision and accuracy. ${ }^{28}$ Linearity was evaluated through analytical curves of the spiked matrix in six concentration levels: 2.4, 3.0, 3.6, 4.2, 4.8 and $5.4 \mu \mathrm{g} \mathrm{L} \mathrm{L}^{-1}$, with three independent replicates for each level. The linear regression parameters were estimated by the least squares method and based on the regression residues analysis, with maximum exclusion of $22.2 \%$ of data (Jackknife test). Linear regression residues were evaluated by normality parameters (Ryan and Joiner test), homoscedasticity (Brown and Forsythe test) and independence (Durbin and Watson test). Analysis of variance (ANOVA) was applied to the analytical curves to verify how much the regression line explains the values that were used to make the linearity adjustment.

The matrix effect was evaluated by injecting the compounds in pure solvent (acetonitrile) and in matrix extract, both containing the two contaminants at the concentrations of $2.4,3.6$ and $4.8 \mu \mathrm{g} \mathrm{L}^{-1}$, and the chromatographic response variation (CRV) was calculated according to equation 1 .

$\operatorname{CRV}(\%)=\frac{\overline{\mathrm{A}}_{\text {matrix }}-\overline{\mathrm{A}}_{\text {solvent }}}{\overline{\mathrm{A}}_{\text {solvent }}} 100$

where $\overline{\mathrm{A}}_{\text {matrix }}$ is the mean of the areas obtained for each compound in the matrix; $\overline{\mathrm{A}}_{\text {solvent }}$ is the mean of the areas obtained for each compound in the solvent.

Selectivity was investigated by comparing chromatograms of extracts of the spiked matrix and the blank (PCDD/Fs-free matrix extract), in six independent replicates.

The limit of quantification (LOQ) was determined by fortifying water samples with the lowest possible amount of 2,3,7,8-TCDF and 2,3,7,8-TCDD that can be quantified using the optimized experimental conditions for the LLE-LTP methodology. The LOQ was considered to be ten times the baseline noise signal of analyte-free samples (blank).

Precision and accuracy were evaluated through experiments that recover analytes from the spiked matrix using two concentration levels, 2.4 and $4.8 \mu \mathrm{g} \mathrm{L}^{-1}$, with seven replicates each. Accuracy was analyzed by the recovery of analytes, with values between 70 and $120 \%$ being considered acceptable. Precision was evaluated by the relative standard deviation (RSD) of replicates, with RSD less than $20 \%$ being the acceptability criterion. ${ }^{28}$

\section{Real samples}

The validated LLE-LTP was applied to analyze tordon pesticide solution samples in the concentration of $0.5 \mathrm{mg} \mathrm{L}^{-1}$. This sample showed substances produced from chlorinated phenols (2,4-dichlorophenoxyacetic acid (2,4-D)), which may have PCDD/Fs in its composition. ${ }^{29}$

Water samples from the sewage treatment plant were analyzed before and after treatment. There are reports in the literature of PCDD/Fs in sewage water, mainly from industrial activities, and treated water due to chlorination during treatment and then exposed to solar radiation. ${ }^{9,30,31}$

Swimming pool water samples were analyzed because they contain high amounts of chlorine and are exposed to the sun daily.

Water samples heated in a microwave oven inside plastic containers (polypropylene (PP) and polyethylene terephthalate (PET)) were analyzed due to the possibility of the formation of PCDD/Fs in the presence of heat and chlorine organic compounds. ${ }^{6,32}$ All samples were analyzed in triplicate.

\section{Results and Discussion}

\section{Optimization of the chromatographic conditions}

The first step of the study was to define the best wavelength for each compound. The absorption spectra (Figure S1, Supplementary Information (SI) section) showed higher absorbance at 200 and $227 \mathrm{~nm}$ for 2,3,7,8-TCDF and 200 and $232 \mathrm{~nm}$ for 2,3,7,8-TCDD. However, the results showed that 227 and $232 \mathrm{~nm}$ were selective (Figure S2, SI section). Therefore, these values were selected for the simultaneous detection of 2,3,7,8-TCDF and 2,3,7,8-TCDD, respectively. Similar studies employed $232 \mathrm{~nm}$ to detect polychlorinated dioxins substituted at positions: $1,2,6,9 ; 1,4,7,8 ; 1,2,3,4 ; 1,2,4,6,9$ and $1,2,3,4,7.26$ 
The second step of this study was to choose the best chromatographic column and mobile phase. The chromatograms obtained from analyses in the Kinetex column showed separate, narrow and acute PCDD/Fs peaks using only acetonitrile as the mobile phase (Figure S3c, SI section). Next, the chromatographic signals obtained from the Poroshell column presented similar results using an acetonitrile/water ratio of 95:05 as the mobile phase (Figure S3b, SI section). However, the Kinetex column provided a larger chromatographic area, and so it was chosen to carry out the next steps in this work.

Several reports ${ }^{17,18,23-27}$ describe the use of acetonitrile and water or methanol and water in different proportions as mobile phase to analyze PCDD/Fs by HPLC. However, the best mobile phase in this study was obtained using only acetonitrile, as can be seen in Figure S3c (SI section). The addition of other solvents such as water or methanol extended peaks decreased their intensity and increased the retention time, as can be observed in Figures S3d and S3e (SI section).

The third step of this work was to choose the best flow rate for the mobile phase. The chromatograms showed that the best flow rate for the mobile phase was $0.5 \mathrm{~mL} \mathrm{~min}^{-1}$, as it reached more intense signals and larger areas for PCDD/Fs peaks (Figure S4, SI section). Similarly, a study performed for analyzing organochlorines (2-chlorophenol and 2,4-dichlorophenol) showed larger chromatographic areas with $0.4 \mathrm{~mL} \mathrm{~min}^{-1} .33$

The fourth step of this study aimed to evaluate the best temperature $\left(30\right.$ and $35^{\circ} \mathrm{C}$ ) of the chromatographic column. The intensity and retention time of the compound peaks were very similar at both temperatures (Figure S5, SI section). Therefore, $30{ }^{\circ} \mathrm{C}$ was chosen because the chromatogram presents a more linear baseline and is in agreement with other studies. ${ }^{23,24}$

The chromatogram obtained in optimized conditions for the simultaneous determination of 2,3,7,8-TCDD and 2,3,7,8-TCDF is shown in Figure 1.

After optimizing the chromatographic conditions for analyzing the PCDD/Fs by HPLC-DAD, the extraction conditions were then optimized for these compounds.

\section{LLE-LTP}

The initial extraction conditions were based on the work of Silvério et al. ${ }^{22}$ In this methodology, the freezing step of the aqueous phase enables separating the phases and cleaning the extract. ${ }^{34}$ In general, a freezing time of $30 \mathrm{~min}$ was enough to separate the phases; however, the aqueous phase remained partially liquid. When the aqueous phase is not completely frozen, a relevant amount of water remains in the organic phase, decreasing the recovery rate and

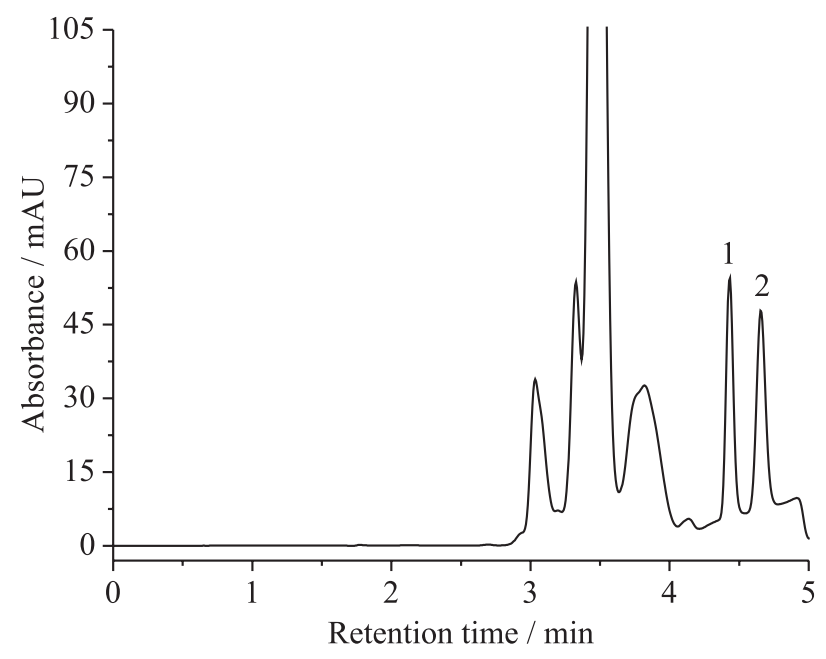

Figure 1. Chromatogram of the $2,3,7,8-\mathrm{TCDF}$ (compound 1) and 2,3,7,8-TCDD (compound 2) standard solution in hexane at concentration of $0.5 \mathrm{mg} \mathrm{L}^{-1}$. Kinetex column, mobile phase $\mathrm{ACN}: \mathrm{H}_{2} \mathrm{O}=100: 0, \mathrm{~T}=30^{\circ} \mathrm{C}$, $\lambda=232 \mathrm{~nm}$, flow rate $=0.5 \mathrm{~mL} \mathrm{~min}^{-1}$.

increasing the drying time of the sample. $1 \mathrm{~h}$ was enough for complete freezing of the aqueous phase and achieved recoveries close to $100 \%$.

Although water and acetonitrile are miscible in all proportions, agitation in vortex for $1 \mathrm{~min}$ is an important parameter of the methodology during application in real samples, since many aqueous samples may have particles and vortexing allow greater efficiency in the homogenization. For this methodology, the vortex was more efficient than the ultrasonic bath and mechanical agitation..$^{35}$ Therefore, the agitation step in the vortex for 1 min was maintained.

Acetonitrile is traditionally used in LLE-LTP as the extraction solvent, ${ }^{22}$ but in this study it was necessary to evaluate the addition of small quantities of non-polar solvents (ethyl acetate) in the organic phase for extracting $\mathrm{PCDD} /$ Fs due to the lipophilic character of these compounds. The two extraction phases reached recovery rates close to $100 \%$, as shown in Figure 2. However, extraction with acetonitrile generated a cleaner chromatogram, i.e., with less signals attributed to interferers (Figure 3). Therefore, acetonitrile was chosen as the appropriate phase for extracting these compounds in water. Similar results were reported by Andrade et al. ${ }^{20}$ and Silvério et al..$^{22}$ using the same extraction phase.

Previous studies have shown that the 8.0/4.0 $\mathrm{mL}$ ratio of organic solvent/water reached the highest extraction rates of the chemical contaminants. ${ }^{36-38}$ Similarly, this study obtained close to $100 \%$ recovery.

The methodology proposed in this study added an extract concentration step. This step reached a concentration factor close to 10 times and, consequently, a quantification limit of $2.4 \mu \mathrm{g} \mathrm{L}^{-1}$ (Table 3). 


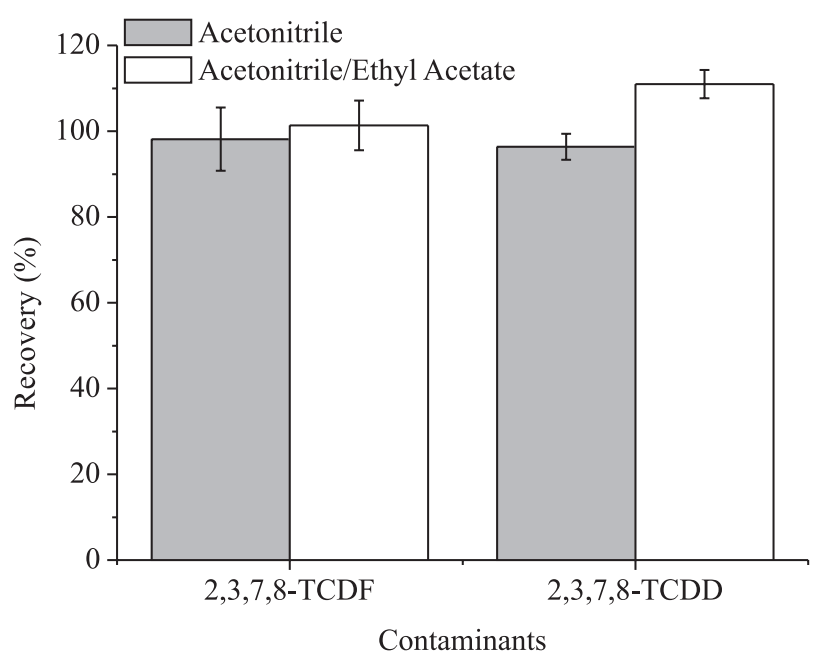

Figure 2. Recovery rate of 2,3,7,8-TCDF and 2,3,7,8-TCDD in the two extraction phases.

The validation step was then initiated after optimizing the extraction conditions of the $\mathrm{PCDD} / \mathrm{Fs}$ from an aqueous matrix.

\section{Methodology validation}

In this work, the LLE-LTP was validated by six of the main figures of merit: linearity, matrix effect, selectivity,

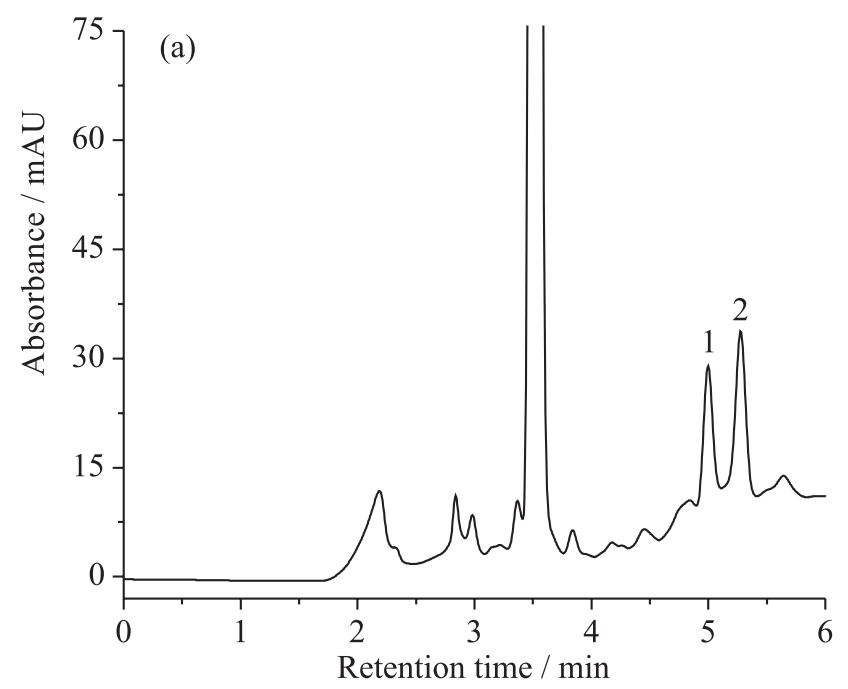

limit of quantification (LOQ), precision and accuracy. ${ }^{28}$ Table 3 shows the main results of the validation study of LLE-LTP to extract 2,3,7,8-TCDF and 2,3,7,8-TCDD from water samples.

\section{Linearity}

Linearity was analyzed through six equidistant concentration levels with three independent replicates for each level, with the LOQ value being the first level of the analytical curve, as can be seen in Figure S6 (SI section). The replicates of each level provided information on the inherent variability of measurements (pure error). The linear regression parameters were estimated by the least squares method (LSM) and based on the analysis of the regression residues, with exclusion of the extreme values being performed (Jackknife test). Thus, 22.2\% of the original data were excluded, thereby obtaining the linear regression residues for 2,3,7,8-TCDF and 2,3,7,8-TCDD, as can be seen in Figures $4 \mathrm{a}$ and $4 \mathrm{~b}$. The least squares method was applied again for each exclusion, thus obtaining the slope, intersection and determination coefficient $\left(\mathrm{R}^{2}\right)$ values shown in Table 3. $\mathrm{R}^{2}$ was greater than 0.99 , indicating the variability of collected data explained by the regression model. ${ }^{39}$ However, it was necessary to evaluate the use of

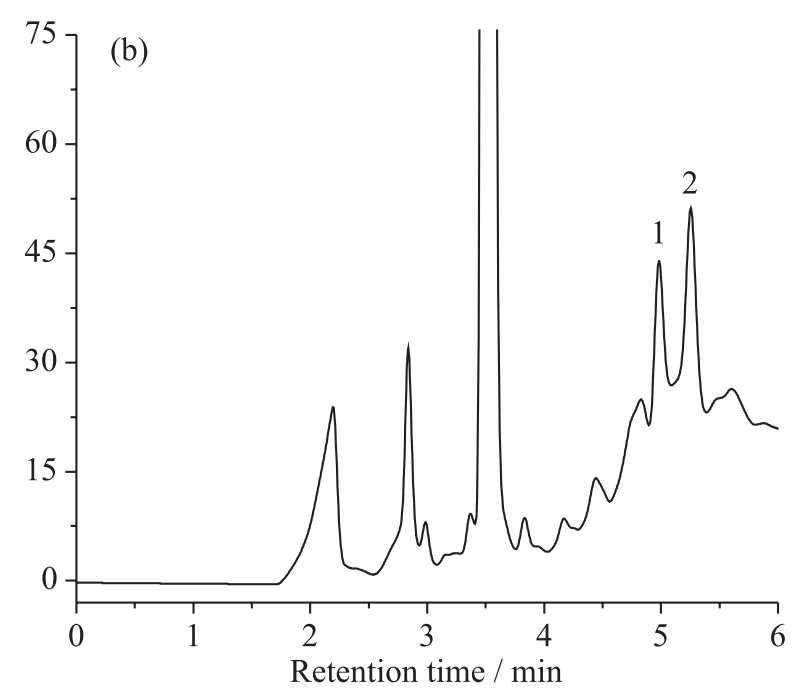

Figure 3. Chromatograms of spiked extract with 2,3,7,8-TCDF (compound 1) and 2,3,7,8-TCDD (compound 2) at $96 \mu \mathrm{g} \mathrm{L}^{-1}$ (a) $\mathrm{ACN}$ and (b) ACN/ACT 6.5/1.5 (v/v).

Table 3. Results of the LLE-LTP validation study of 2,3,7,8-TCDF and 2,3,7,8-TCDD in water samples

\begin{tabular}{|c|c|c|c|c|c|c|}
\hline \multirow{2}{*}{ Analyte } & \multirow{2}{*}{$\begin{array}{l}\text { Linearity range / } \\
\qquad\left(\mu \mathrm{g} \mathrm{L}^{-1}\right)\end{array}$} & \multirow{2}{*}{ Linear equation } & \multirow{2}{*}{$\mathrm{R}^{2}$} & \multicolumn{2}{|c|}{ Recovery \pm RSD / \% } & \multirow{2}{*}{$\mathrm{LOQ} /\left(\mu \mathrm{g} \mathrm{L}{ }^{-1}\right.$} \\
\hline & & & & $2.4 \mu \mathrm{g} \mathrm{L}^{-1} \mathrm{a}$ & $4.8 \mu \mathrm{g} \mathrm{L}^{-1 \mathrm{a}}$ & \\
\hline $2,3,7,8-\mathrm{TCDF}$ & $2.4-5.4$ & $y=255578.6 x-6551.7$ & 0.9903 & $98.1 \pm 4.5$ & $107.0 \pm 5.2$ & 2.4 \\
\hline 2,3,7,8-TCDD & $2.4-5.4$ & $y=208888.6 x+734420.5$ & 0.9908 & $104.4 \pm 6.6$ & $102.1 \pm 3.0$ & 2.4 \\
\hline
\end{tabular}

${ }^{\mathrm{a}}$ Mean of seven replicates. $\mathrm{R}^{2}$ : determination coefficient; RSD: relative standard deviations; LOQ: limit of quantification; 2,3,7,8-TCDF: 2,3,7,8-tetrachlorodibenzofuran; 2,3,7,8-TCDD: 3,7,8-tetrachlorodibenzo- $p$-dioxin. 
the LSM through propositions related to regression residues (normality, homoscedasticity and independence) and make an adjustment to the linear model (ANOVA).

The normality of regression residues was evaluated by the Ryan-Joiner test, i.e., a graph showing the normal probability of regression residues was constructed (Figures $4 \mathrm{c}$ and $4 \mathrm{~d}$ ).
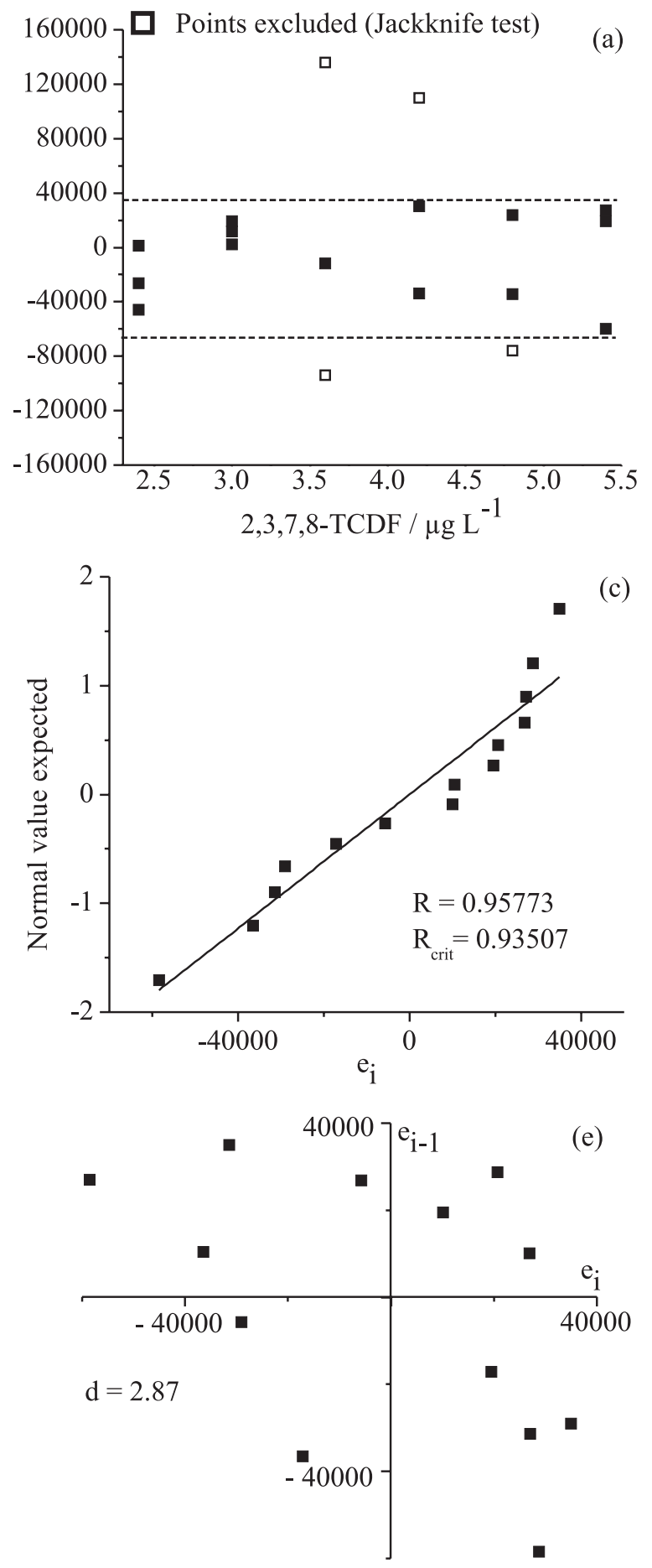

The correlation coefficients found in the graphs were higher than the critical correlation coefficient $(0.93507)$ obtained by polynomial interpolation; therefore, it could be concluded (with a significance level of 0.05) that residues followed normal distribution, thus allowing the use of hypothesis tests that follow this type of distribution.
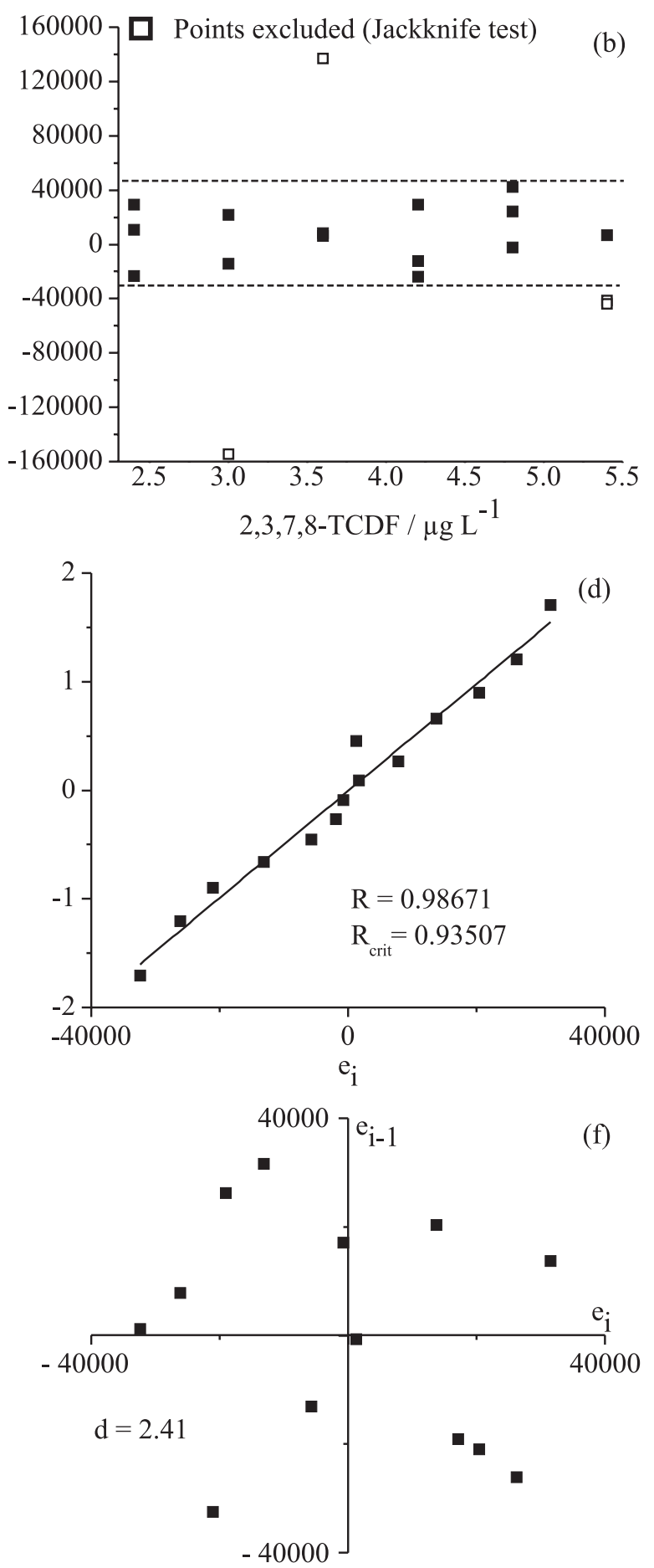

Figure 4. Graphs obtained in the linearity study of the LLE-LTP methodology. Linear regression residues for 2,3,7,8-TCDF (a) and 2,3,7,8-TCDD (b), after the exclusion of extreme values (Jackknife test). Normal probability of regression residues for 2,3,7,8-TCDF (c) and 2,3,7,8-TCDD (d). Autocorrelation of regression residues for 2,3,7,8-TCDF (e) and 2,3,7,8-TCDD (f). $\mathrm{e}_{\mathrm{i}}$ : residual; R: correlation coefficient of Ryan-Joiner test; d: Durbin-Watson statistics. 
The homoscedasticity of regression residues was investigated by the Brown-Forsythe test, which determines the existence of differences between variances of residues through an adaptation of the Levene test. The distribution of regression residues along the concentration levels studied was homogeneous, thus confirming homoscedasticity.

The independence of regression residues was analyzed by the Durbin-Watson test and no autocorrelation was observed at the significance level of 0.05 . A graphical representation of data was performed to confirm this result, and a random distribution of residues in the four quadrants was obtained demonstrating their independence, as can be seen in Figures $4 \mathrm{e}$ and $4 \mathrm{f}$.

The data were adjusted to the linear model throughout the assessed range from 2.4 to $5.4 \mu \mathrm{g} \mathrm{L}^{-1}$ (Table 3), with significant regression and non-significant linearity deviation at the significance level of 0.05 . Therefore, it could be concluded that the LSM was adequate for the studied data. All linearity assessments followed procedures proposed by Souza and Junqueira ${ }^{40}$ and Bazilio et al. ${ }^{41}$

\section{Matrix effect}

The matrix effect was evaluated by comparing the chromatographic response of the two analytes in acetonitrile and in matrix extract obtained from the LLE-LTP. The results showed an underestimation of the 2,3,7,8-TCDF response to HPLC-DAD, i.e., negative effect. This effect was more pronounced at higher concentrations and an overestimation was observed for 2,3,7,8-TCDD, indicating a positive effect which was higher at lower concentrations. Previous reports showed that the matrix effect is very common in complex matrices

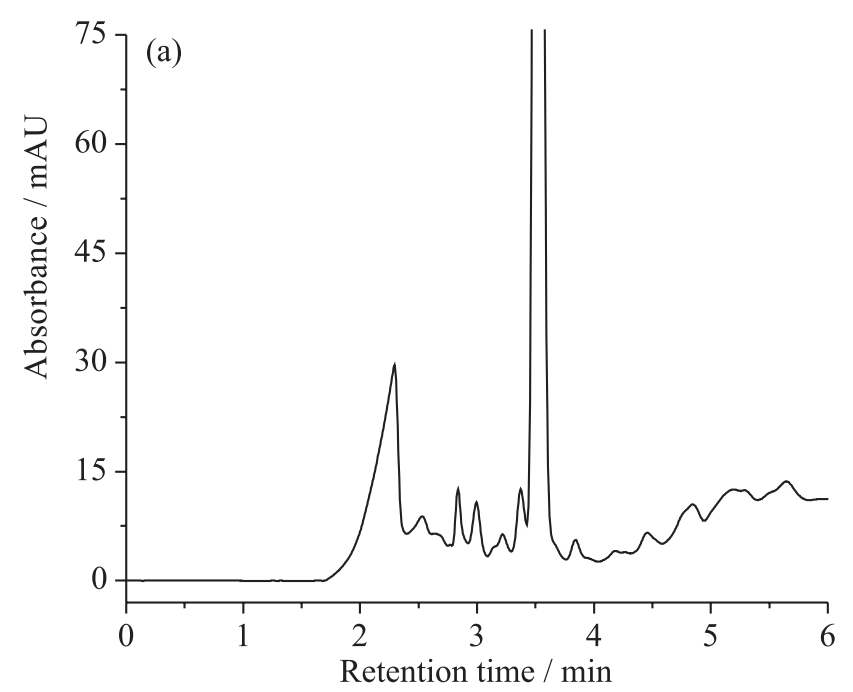

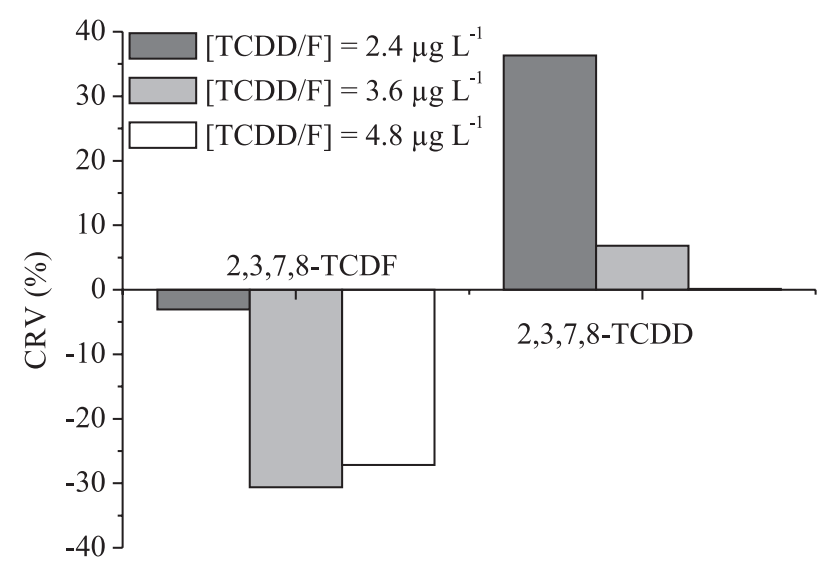

Figure 5. Chromatographic response variation (CRV) of 2,3,7,8-TCDF and 2,3,7,8-TCDD in acetonitrile and matrix extract.

such as sewage sludge and soil, ${ }^{42}$ and less significant in less complex matrices such as water, fruits and juice. ${ }^{33}$ However, the matrix effect in this study was detected in aqueous matrix, as shown in Figure 5.

\section{Selectivity}

The LLE-LTP showed selectivity for 2,3,7,8-TCDF and 2,3,7,8-TCDD due to the absence of chromatographic signals interfering in the retention time of compounds analyzed in blank samples (analyte-free matrix extract), as shown in Figure 6a.

Limit of quantification

The LOQ is the lowest concentration that the methodology can operate with acceptable precision. ${ }^{28}$ Therefore, the limit of quantification (LOQ) of the

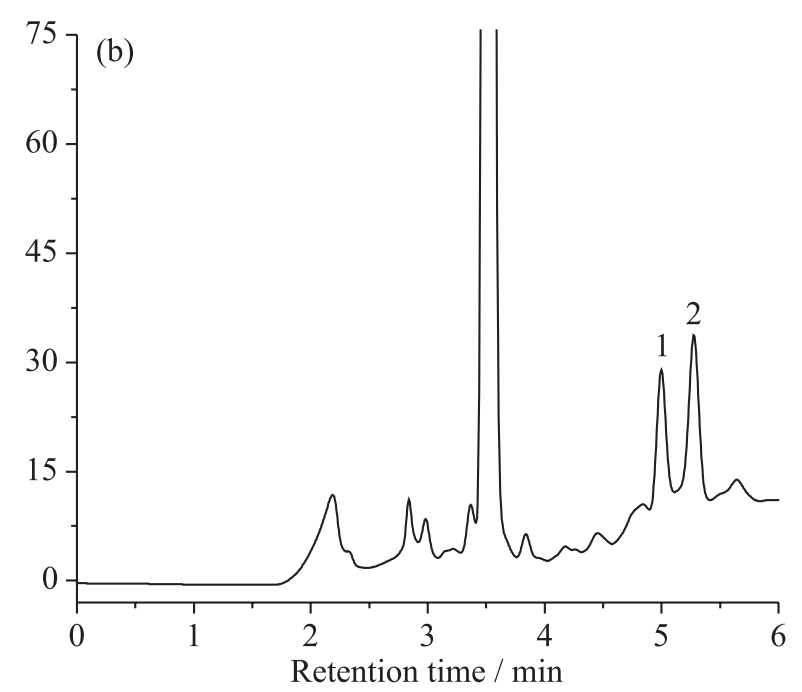

Figure 6. Chromatograms of analyte-free matrix extract, i.e., blank (a) and spiked extract with 2,3,7,8-TCDF (compound 1) and 2,3,7,8-TCDD (compound 2) at $96 \mu \mathrm{g} \mathrm{L}^{-1}$ (b). 
LLE-LTP methodology proposed in this work for both compounds was $2.4 \mu \mathrm{g} \mathrm{L} \mathrm{L}^{-1}$ (Table 3).

A previous study using cloud-point extraction coupled with HPLC-DAD did not determine the LOQ value, but it indicated the working range from 1 to $128 \mu \mathrm{g} \mathrm{L}^{-1} .^{18}$ Similarly, another study also did not determine the LOQ value using microwave-assisted extraction and HPLC-DAD, but it indicated the working concentration of $0.45 \mu \mathrm{g} \mathrm{L}{ }^{-1} .25$

The liquid-liquid extraction combined with HPLC-DAD was only used to analyze $2,3,7,8-\mathrm{TCDF}$, reaching the LOQ of $0.3 \mu \mathrm{g} \mathrm{L} \mathrm{L}^{-1}$, being a lower value to that found in this study. ${ }^{24}$ It is worth mentioning that this has been the first work that analyzes these two compounds simultaneously using this methodology.

\section{Accuracy and precision}

The accuracy and precision of the methodology were simultaneously evaluated for concentration levels of 2.4 and $4.8 \mu \mathrm{g} \mathrm{L}^{-1}$ with seven replicates each. The average recovery percentages of analytes from the spiked matrix and RSD are presented in Table 3. The methodology was accurate and precise, as the recovery percentage of analytes (98.1 to $107 \%$ ) (Table 3) and RSD (3.0 to 6.6\%) (Table 3) are within the range recommended by the International Union of Pure and Applied Chemistry (IUPAC), ${ }^{28}$ which establishes recovery ranging from 70 to $120 \%$, and RSD less than $20 \%$.

\section{Real samples}

After methodology validation, LLE-LTP was used to analyze different water samples. The results showed that PCDD/Fs were not detected in any of the analyzed samples. A similar result was found in applying cloudpoint extraction and HPLC-UV to water samples from the Canary Islands, Spain, but it did not find dioxins. ${ }^{18}$ However, PCDD/Fs were quantified in water samples collected in Shenzhen, China, before $\left(32.93 \mathrm{pg} \mathrm{L}^{-1}\right)$ and after $\left(0.64 \mathrm{pg} \mathrm{L}^{-1}\right)$ treatment using HRGC-HRMS. ${ }^{31}$ In Brazil, the toxic equivalency (TEQ) of PCDD/Fs was determined in soil samples ( 0.43 to $4.54 \mathrm{ng}$ TEQ $\left.\mathrm{kg}^{-1}\right)$ using accelerated solvent extraction and GC-HRMS. ${ }^{5}$ Previous works quantified PCDD/Fs (0.96 to 3.17 TEQ pg g $^{-1}$ (2,3,7,8-TCDD) and $1.91 \mathrm{pg} \mathrm{g}^{-1}(2,3,7,8$-TCDF) $)$ in fresh milk from southwest Iran using liquid-liquid extraction and HPLC-UV. ${ }^{23,24}$ The presence of $\mathrm{PCDD} / \mathrm{Fs}$ in real samples depends on several factors such as matrix type, analyte concentration, sample collection period and extraction and detection methodologies used; therefore, most of the literature studies did not quantify PCDD/Fs in real samples. ${ }^{1,17,18,20,25,26}$

\section{Conclusions}

The LLE-LTP coupled with HPLC-DAD was faster, simpler and required fewer sample handling steps than many methodologies described in literature for analyzing 2,3,7,8-TCDD and 2,3,7,8-TCDF in aqueous matrices. In addition, this methodology was efficient, low cost and used minimal organic solvent. The extracts are cleaned, and no subsequent "clean-up" steps are required. The methodology validation enabled evaluating the main figures of merit (precision, accuracy, linearity, matrix effect and selectivity) to certify the reliability of results. The detectability levels found by this methodology are similar to other methodologies using the same detection systems, mainly due to the achieved concentration factor. The results for real samples did not detect any PCDD/Fs in the studied samples.

\section{Supplementary Information}

Supplementary data are available free of charge at http://jbcs.sbq.org.br as a PDF file.

\section{Acknowledgments}

The authors thank the Conselho Nacional de Desenvolvimento Científico e Tecnológico (CNPq) (420637/2016-8 and 307381/2015-3) for the financial support from research fellowships. The authors are also grateful to the Fundação de Amparo à Pesquisa do Estado de Minas Gerais (FAPEMIG) (APQ-01429-16), Coordenação de Aperfeiçoamento de Pessoal de Nível Superior (CAPES) and the Universidade Federal de Minas Gerais (UFMG), for the infrastructure provided.

\section{References}

1. Sikiti, P.; Msagati, T. A. M.; Mishra, A. K.; Mamba, B. B.; Phys. Chem. Earth 2012, 50, 98.

2. Salamanca, M.; Chandía, C.; Hernández, A.; Sci. Total Environ. 2016, 573, 1397.

3. Thuan, N. T.; Tsai, C. L.; Weng, Y. M.; Lee, T. Y.; Chang, M. B.; Chemosphere 2011, 83, 760.

4. Xie, H. Q.; Xia, Y.; Xu, T.; Chen, T.; Fu, H.; Li, Y.; Luo, Y.; Xu, L.; Tsim, K. W. K.; Zhao, B.; Environ. Pollut. 2018, 235, 965.

5. Pussente, I. C.; ten Dam, G.; van Leeuwen, S.; Augusti, R.; J. Braz. Chem. Soc. 2017, 28, 858.

6. Metelkova, L.; Zhakovskaya, Z.; Kukhareva, G.; Rybalko, A.; Nikiforov, V.; Environ. Sci. Pollut. Res. 2018, DOI: 10.1007/ s11356-018-1945-y.

7. Sadowska, A.; Nynca, A.; Ruszkowska, M.; Paukszto, L.; Myszczynski, K.; Orlowska, K.; Swigonska, S.; Molcan, T.; 
Jastrzebski, J. P.; Ciereszko, R. E.; Chemosphere 2017, 178, 368.

8. Ábalos, M.; Cojocariu, C. I.; Silcock, P.; Roberts, D.; Pemberthy, D. M.; Sauló, J.; Abad, E.; Anal. Bioanal. Chem. 2016, 408, 3511.

9. Vallejo, M.; Román, M. F. S.; Ortiz, I.; Irabien, A.; Chemosphere 2015, 118, 44.

10. https://www.epa.gov/ground-water-and-drinking-water, accessed in June 2018.

11. Resolução CONAMA No. 430/2011; Dispõe sobre Condições e Padrões de Lançamento de Efluentes; DOU No. 92, de 16/05/2011, available at http://www.mma.gov.br/port/conama/ legiabre.cfm?codlegi=646, accessed in July 2018.

12. Resolução CONAMA No. 357/2005; Dispõe sobre a Classificação dos Corpos de Água e Diretrizes Ambientais para o seu Enquadramento, bem como Estabelece as Condições e Padrões de Lançamento de Efluentes, e dá outras Providências; DOU No. 053, de 18/03/2005, available at: http://www.mma. gov.br/port/conama/legiabre.cfm?codlegi $=459$, accessed in July, 2018.

13. Youn, Y. Y.; Park, D. H.; Lee, Y. H.; Lim, Y. H.; Cho, H. S.; Chemosphere 2015, 118, 124.

14. Choi, J. W.; Lee, J. H.; Moona, B. S.; Baeka, K. H.; J. Chromatogr. A 2007, 1157, 17.

15. Prado, L. S.; Llompart, M.; Lores, M.; Jares, C. G.; Bayona, J. M.; Cela, R.; Chemosphere 2006, 65, 1338.

16. Yabuta, H.; Fukushima, M.; Tanaka, F.; Ichikawa, H.; Tatsumi, K.; Anal. Sci. 2004, 20, 787.

17. Fernández, A. E.; Ferrera, Z. S.; Rodríguez, J. J. S.; Analyst 1999, 124, 487.

18. Sanz, C. P.; Ferrera, Z. S.; Rodriguez, J. J. S.; Anal. Chim. Acta 2002, 470, 205.

19. United States Environmental Protection Agency (US EPA); Method 1613, Tetra-Through Octa-Chlorinated Dioxins and Furans by Isotope Dilution HRGC/HRMS; Engineering and Analysis Division (4303): Washington D.C., USA, 1994.

20. Andrade, V. F.; Durães, A. F. S.; Cassimiro, D. L.; de Pinho, G. P.; Silvério, F. O.; J. Environ. Sci. Health, Part B 2017, 52, 267.

21. Maia, M. R.; Arcanjo, A. L. P.; Pinho, G. P.; Silvério, F. O.; J. Braz. Chem. Soc. 2017, 28, 179.

22. Silvério, F. O.; Silva, J. G. S.; Aguiar, M. C. S.; Cacique, A. P.; de Pinho, G. P.; Quim. Nova 2012, 35, 2052.

23. Rezaei, M.; Khorasgani, Z. N.; Nakisa, A.; Imani, N.; Rezaee, S.; Khodayar, M. J.; Kalantari, H.; J. Environ. Anal. Toxicol. 2015, 5, 301.
24. Nakisa, A.; Khorasgani, Z. N.; Rezaei, M.; Imani, N.; Rezaee, S.; Food Nutr. Sci. 2015, 6, 955.

25. Yang, J. S.; Lee, D. W.; Lim, H.; J. Liq. Chromatogr. Relat. Technol. 2003, 26, 803.

26. Sirimanne, S. R.; Barr, J. R.; Patterson, D. G.; Anal. Chem. 1996, 68, 1556.

27. Fernández, A. E.; Ferrera, Z. S.; Rodriguez, J. J. S.; Chromatographia 2001, 53, 375.

28. Thompson, M.; Ellison, S. L. R.; Wood, R.; Pure Appl. Chem. 2002, 74, 835 .

29. Kaioumova, D.; Kaioumova, F.; Opelz, G.; Susal, C.; Chemosphere 2001, 43, 801.

30. Sappington, E. N.; Balasubramani, A.; Rifai, H. S.; Chemosphere 2015, 133, 82 .

31. Lu, F.; Jiang, Y.; Wu, D.; Zhou, J.; Li, S.; Zhang, J.; Environ. Pollut. 2016, 211, 233.

32. Nestrick, T. J.; Lamparski, L. I.; Cramm, R. H.; Chemosphere 1991, 22, 215.

33. Kadmi, Y.; Favier, L.; Yehya, T.; Soutrel, I.; Simion, A. I.; Vial, C.; Wolbert, D.; Arabian J. Chem., in press, DOI: 10.1016/j. arabjc.2015.06.005.

34. Costa, A. I. G.; Queiroz, M. E. L. R.; Neves, A. A.; Sousa, F. A.; Zambolim, L.; Food Chem. 2015, 181, 64.

35. Pinho, G. P.; Neves, A. A.; Queiroz, M. E. L. R.; Silvério, F. O.; Food Control 2010, 21, 1307.

36. Vieira, H. P.; Neves, A. A.; Queiroz, M. E. L. R.; Quim. Nova 2007, 30, 535.

37. Goulart, S. M.; Alves, R. D.; Neves, A. A.; Queiroz, J. H.; Assis, T. C.; Queiroz, M. E. L. R.; Anal. Chim. Acta 2010, 671, 41.

38. Pinho, G. P.; Silvério, F. O.; Evangelista, G. F.; Mesquita, L. V.; Barbosa, E. S.; J. Braz. Chem. Soc. 2014, 25, 1292.

39. Montgomery, D. C.; Runger, G. C.; Estatística Aplicada e Probabilidade para Engenheiros, 5a ed.; LTC: Rio de Janeiro, Brasil, 2009.

40. Souza, S. V.; Junqueira, R. G.; Anal. Chim. Acta 2005, 552, 25.

41. Bazilio, F. S.; Bomfim, M. V. J.; Almeida, R. J.; Abrantes, S. M. P.; Rev. Anal. 2012, 59, 60.

42. Pinho, G. P.; Neves, A. A.; Queiroz, M. E. L. R.; Silvério, F. O.; Quim. Nova 2009, 32, 987.

Submitted: October 15, 2018 Published online: February 7, 2019 